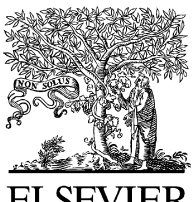

\title{
Modification upon aging of the density of presynaptic modulation systems in the hippocampus
}

\author{
Paula M. Canas ${ }^{1}$, João M.N. Duarte ${ }^{1}$, Ricardo J. Rodrigues ${ }^{1}$, \\ Attila Köfalvi ${ }^{1}$, Rodrigo A. Cunha* \\ Centre for Neuroscience of Coimbra, Institute of Biochemistry, Faculty of Medicine, University of Coimbra, \\ Rua Larga, 3004-504 Coimbra, Portugal
}

Received 30 October 2007; received in revised form 29 December 2007; accepted 8 January 2008

\begin{abstract}
Different presynaptic neuromodulation systems have been explored as possible targets to manage neurodegenerative diseases. However, most studies used young adult animals whereas neurodegenerative diseases are prevalent in the elderly. Thus, we now explored by Western blot analysis how the density of different presynaptic markers and receptors changes with aging in rat hippocampal synaptosomes (purified nerve terminals). Compared to synaptosomal membranes from 2-month-old rats, the density of presynaptic proteins (synaptophysin or SNAP-25) decreased at 18-24 months. In parallel, markers of glutamatergic terminals (vGluT1 or vGluT2) and cholinergic terminal markers (vAChT) constantly decreased with aging from 12 to 18 months onwards, whereas the densities of GABAergic (vGAT) only decreased after 24 months. Inhibitory $A_{1}$ and $\mathrm{CB}_{1}$ receptor density tended to decrease with aging, whereas facilitatory mGluR5 and P2Y1 receptor density was roughly constant and facilitatory $\mathrm{A}_{2 \mathrm{~A}}$ receptor density increased at 18-24 months. Thus aging causes an imbalance of excitatory versus inhibitory nerve terminal markers and causes a predominant decrease of inhibitory rather than facilitatory presynaptic modulation systems.
\end{abstract}

(C) 2008 Elsevier Inc. All rights reserved.

Keywords: Aging; Nerve terminals; Density; Adenosine; $\mathrm{A}_{1} ; \mathrm{A}_{2 \mathrm{~A}} ; \mathrm{CB}_{1}$; P2Y1; Metabotropic; Glutamate; MGluR5; GABA; Acetylcholine; Synaptophysin

\section{Introduction}

There is increasing evidence indicating that dysfunction and loss of nerve terminals might represent one of the earliest modifications in the course of neurodegenerative diseases (Wishart et al., 2006). For instance, in Alzheimer's disease, the loss of synaptic markers, in contrast to neuronal loss, is the parameter that correlates better with memory dysfunction (Selkoe, 2002). Likewise, in Parkinson's disease, modification of firing patterns of cortico-striatal pathways (Bézard et al., 2003) and loss of dopaminergic terminals (Herkenham et al., 1991) occur early in the asymptomatic

\footnotetext{
* Corresponding author. Tel.: +351 239820190; fax: +351 239822776.

E-mail address: racunha@ci.uc.pt (R.A. Cunha). URL: http://www/cnc.cj.uc.pt/lab_lef/ (R.A. Cunha).

1 These authors contributed experimentally for the present work. The authors are grateful to Dr. Ken Mackie for generously supply of the $\mathrm{CB}_{1}$ receptor antibody.
}

phase of the disease. In fact, this synaptic dysfunction and damage has been recognised as an early event in the course of different other neurodegenerative diseases such as Huntington's (Li et al., 2001), prion's diseases (Ferrer, 2002), HIV infection (Garden et al., 2002), schizophrenia (Glantz et al., 2006), temporal lobe epilepsy (Ratté and Lacaille, 2006) or motor neuropathies (Raff et al., 2002).

This central and initial role of synaptic dysfunction in neurodegenerative diseases has been the main driving force to conceive presynaptic neuromodulation systems as candidate targets to restraint the early modifications in these diseases. Thus, drugs activating presynaptic modulators such as adenosine $A_{1}$ receptors (Fredholm et al., 2005) or cannabinoid $\mathrm{CB}_{1}$ receptors (van der Stelt and Di Marzo, 2005) might afford protection against different neurodegenerative diseases. Also, antagonists of adenosine $\mathrm{A}_{2 \mathrm{~A}}$ receptors (Fredholm et al., 2005), metabotropic group 5 receptors (Flor et al., 2002) or ATP P2Y1 receptors (Franke et al., 2006) also confer neu- 
roprotection in different animal models of brain degenerative diseases. However, the study of novel neuroprotective strategies has mostly been carried out using young adult animals, whereas most neurodegenerative diseases are prevalent in the elderly. The extrapolation of the conclusions reached in young adult animals to the context of disease progression in the elderly can only be tentatively suggested provided that there is no significant aging-related modification of the targeted presynaptic modulation systems. As a first step to tackle this question, we now explored by Western blot analysis how the density of different presynaptic markers and of receptors triggering different presynaptic modulation systems changed with aging in rat hippocampal nerve terminals.

\section{Methods}

Male Wistar rats, young adults ( 2 months), adults (6 and 12 months) and aged (18 and 24 months), were obtained from Charles River (Barcelona, Spain). They were handled according with the EU guidelines for use of experimental animals (86/609/EEC), the rats being anesthetized under halothane atmosphere before being sacrificed by decapitation.

\subsection{Preparation of hippocampal nerve terminals}

Nerve terminals from the rat hippocampus were purified through sucrose and Percoll gradients (Rebola et al., 2005; Rodrigues et al., 2005a). We have already validated the use of these hippocampal synaptosomes to study age-related modifications of biochemical and functional properties of nerve terminals (Cunha et al., 2001; Lopes et al., 1999; Rebola et al., 2003a; Rodrigues et al., in press). Briefly, hippocampal tissue was homogenized in a medium containing $0.32 \mathrm{M}$ sucrose, $1 \mathrm{mM}$ EDTA, $0.1 \%$ BSA and $10 \mathrm{mM}$ HEPES (pH 7.4). The homogenate was spun for $10 \min 3000 \times g$ at $4{ }^{\circ} \mathrm{C}$ and the supernatant spun again at $14,000 \times g$ for $12 \mathrm{~min}$. The pellet (P2 fraction) was resuspended in $1 \mathrm{ml}$ of Percoll $45 \%$ (v/v) in Krebs-HEPES-Ringer (KHR) medium (in $\mathrm{mM}: \mathrm{NaCl}$ 140, EDTA 1, KCl 5, glucose 5 and HEPES 10, pH 7.4) and spun again at $14,000 \times g$ for $2 \mathrm{~min}$. Synaptosomes were then removed from the top layer, washed once with KHR medium and resuspended in SDS-PAGE buffer (see below) for Western blot analysis.

\subsection{Western blot analysis}

The density of general cellular markers (tubulin and GADPH), of general markers of nerve terminals (synaptophysin and SNAP-25), of markers of the phenotype of different nerve terminals (vGluT1 and 2, vGAT and vAChT) and of different neuromodulation system that have been involved in the control of neurodegeneration (adenosine $A_{1}$ and $A_{2 A}$, cannabinoid $C B_{1}$, glutamate mGluR5 and purinergic P2Y1 receptors) was compared in hippocampal nerve terminals derived from rats with different ages
(2, 6, 12, 18 and 24 months) by Western blot analysis. Briefly, after determining the amount of protein, each sample was diluted with five volumes of SDS-PAGE buffer containing $30 \%(\mathrm{v} / \mathrm{v})$ glycerol, $0.6 \mathrm{M}$ dithiothreitol, $10 \%$ $(\mathrm{w} / \mathrm{v}) \mathrm{SDS}$ and $375 \mathrm{mM}$ Tris- $\mathrm{HCl} \mathrm{pH} 6.8$, boiled at $95^{\circ} \mathrm{C}$ for $5 \mathrm{~min}$. These diluted samples (each gel always included samples from the different age groups for direct comparison) and the pre-stained molecular weight markers (Amersham Biosciences, UK) were separated by SDS-PAGE (10\% with a $4 \%$ concentrating gel) under reducing conditions and electro-transferred to polyvinylidene difluoride membranes $(0.45 \mu \mathrm{m}$, from Amersham). After blocking for $2 \mathrm{~h}$ at room temperature with $5 \%$ milk in Tris-buffered saline, pH 7.6 containing $0.1 \%$ Tween 20 (TBS-T), the membranes were incubated overnight at $4{ }^{\circ} \mathrm{C}$ with the different antibodies, namely: widely used mouse anti- $\alpha$ tubulin (1:10,000 dilution, from Sigma-Portugal) and goat anti-glyceraldeheyde-3-phosphate dehydrogenase (GAPDH, 1:1000 dilution, from Santa Cruz Biotechnology, Alfagene, Portugal); previously validated (see Pinheiro et al., 2003) mouse anti-synaptophysin (1:1000, from Sigma) and mouse anti-SNAP-25 (1:10,000, from Sigma); previously used (e.g. Köfalvi et al., 2005) guinea-pig anti-vesicular GABA transporter (vGAT, 1:1000, from Calbiochem, PGHitec, Portugal), guinea-pig anti-vesicular glutamate transporters types 1 and 2 (vGluT1 and vGluT2, 1:5000, from Chemicon) and guinea-pig anti-vesicular acetylcholine transporter (vAChT, 1:500, from Chemicon); previously validated rabbit anti-adenosine $A_{1}$ receptor (1:1000, from Affinity Bioreagents, Golden, USA; see Rebola et al., 2003b), goat anti-adenosine $\mathrm{A}_{2 \mathrm{~A}}$ receptor (1:500 dilution, from Santa Cruz Biotechnology; see Rebola et al., 2005), rabbit L-15 Cterminus anti-CB ${ }_{1}$ receptor (1:500, generously supplied by Dr. Ken Mackie, Indiana University, Bloomington, USA; see Köfalvi et al., 2005), rabbit anti-mGluR5 receptor (1:3000, from Upstate Biotechnology; see Rodrigues et al., 2005b) and goat anti-P2Y1 receptor (1:200, from Santa Cruz Biotechnology; see Rodrigues et al., 2005a). After four washing periods for $10 \mathrm{~min}$ with TBS-T containing $0.5 \%$ milk, the membranes were incubated with the alkaline phosphatase-conjugated anti-goat, anti-rabbit, anti-mouse or anti-guinea-pig secondary antibody (1:2000, from Amersham) in TBS-T containing $1 \%$ milk during $90 \mathrm{~min}$ at room temperature. After five 10 min washes in TBS-T with $0.5 \%$ milk the membranes were incubated with enhanced chemifluorescence during $5 \mathrm{~min}$ and then analysed with a VersaDoc 3000 (Biorad). The membranes were always re-probed, so that at least two different measures in each probed membrane were obtained (internal normalization of data). Briefly, the membranes were first incubated for 30 min with $40 \%$ methanol, then for $1 \mathrm{~h}$ at room temperature with a $0.1 \mathrm{M}$ glycine $(\mathrm{pH} 2.2)$ solution and then blocked as previously described before incubation with one of the primary antibodies listed above. The membranes were then washed and incubated with alkaline phosphatase-conjugated secondary antibody as described. 


\subsection{Statistics}

Values are mean \pm S.E.M. of $n$ experiments. The significance of the effects of age was estimated with one-way ANOVA followed by Duncan's post hoc test. A value of $P<0.05$ was considered to represent a significant difference.

\section{Results and discussion}

When we investigated the age-related changes of the density of proteins integrating the vesicular excoytotic machinery, we found that the density of these proteins, often used as synaptic markers, was different in the different age groups. In fact, as shown in Fig. 1A, the densities of synaptophysin (a protein present in synaptic vesicles; see Pinheiro et al., 2003, and references therein) as well as the density of SNAP-25 (a membrane protein located in the active zone of nerve terminals; see Pinheiro et al., 2003, and references therein) were larger $(P<0.05, n=5-8)$ at 6 and 12 months compared to 2 months (12-15\% for synaptophysin and 21-24\% for SNAP-25). In contrast, the density of both proteins decreased $(P<0.05, n=4-8)$ at 18 months $(12.4 \pm 4.2 \%$ for synaptophysin and $13.3 \pm 4.6 \%$ for SNAP$25, n=5)$ and 24 months $(28.3 \pm 3.5 \%$ for synaptophysin and $48.5 \pm 5.1 \%$ for SNAP-25, $n=6)$. When the densities of two cytoplasmatic proteins ( $\alpha$-tubulin or GAPDH) were used as normalizing factors instead of total protein, synaptic proteins still showed a significant decrease upon aging (18-24 months). However, by this measurement, levels of synaptic proteins were not significantly increased after 6-12 months because $\alpha$-tubulin and GAPDH densities were also higher at 6-12 months compared to 2 months (Fig. 1B). This increase of the density of $\alpha$-tubulin and GAPDH might be rather non-specific and reflect changes in levels of proteins related with 'house-keeping' functions at 6-12 months of age. Therefore, it is concluded that there is a modification of the density of the tested proteins associated with the vesicular release apparatus which might slightly increase during adulthood and then significantly decreases upon aging. This age-related decrease of presynaptic markers is in general agreement with the majority of studies reporting a decrease in synaptophysin mRNA and protein density and in the number of elements immuno-positive for synaptophysin with aging in the hippocampus and various cortical structures (Chen et al., 1995; Eastwood et al., 1994; Frick and Fernandez, 2003; King and Arendash, 2002; Masliah et al., 1993; Rutten et al., 2005; Saito et al., 1994), albeit some studies reported lack of modification (Calhoun et al., 1998; Eastwood et al., 2006; Nicolle et al., 1999a) and even increases (Benice et al., 2006; Himeda et al., 2005) in the density of this presynaptic marker.

We next investigated if there was an age-related different modification of the different types of nerve terminals. For that purpose, we investigated the density of markers of dif- ferent types of nerve terminals, namely vesicular glutamate transporters (vGluT1 and 2), vesicular GABA transporters (vGAT) and vesicular cholinergic transporters (vAChT). As illustrated in Fig. 1C, there was an age-related continuous decrease of vGluT1 (significant after 18 months) and of vGluT2 (significant after 12 months). This same pattern was observed for vAChT (Fig. 1E), which density tended to continuously decrease with age (significant after 18 months), supporting a loss of cholinergic innervation upon aging in the hippocampus (see Sarter and Bruno, 2004). In contrast, we found that the age-related change in the density of vGAT displayed a biphasic profile, with an increase at 6 months and a decrease at 24 months (Fig. 1D). However, if vGAT density was normalized by comparison with the density of cytoplasmatic markers ( $\alpha$-tubulin and GAPDH), the initial increase of vGAT density at 6 months was offset (since the density of $\alpha$-tubulin and GAPDH increased at 6-12 months, see Fig. 1B) but the decrease at 24 months was still significant $(P<0.05)$. To the best of our knowledge, this constitutes the first description of age-related changes in the density of these vesicular transporters that are widely used to discriminate between different types of nerve terminals. The results obtained indicate that there is a different age-related modification of the density of these markers of different nerve terminals, suggesting that there is an initial decrease of excitatory nerve terminals (glutamatergic and cholinergic) later followed by GABAergic nerve terminals but with lower amplitude. This suggests a potential imbalance between excitation and inhibition in hippocampal circuits in favor of inhibition, which would agree with the proposed imbalance towards inhibition as a substrate of aging-associated cognitive impairment (Wong et al., 2006). However, it should be noted that electrophysiological evaluation of excitatory versus inhibitory inputs into cortical pyramidal neurons did not reveal an imbalance with aging (Wong et al., 2000), although previous morphological studies showed that the age-related decline of inhibitory buttons is region-selective within the hippocampus (Shi et al., 2004). In this respect, it is important to keep in mind that the present study only investigated global changes of the density of different presynaptic markers in the whole hippocampus. Since it is known that there are different age-related changes in different hippocampal circuits (Barnes, 1994), further studies should be designed to investigate if there are different age-related changes of these presynaptic markers in different hippocampal areas. Therefore, although tempting, further studies are warranted to test if an imbalance between the strength of excitatory and inhibitory innervations may underlie age-related neurophysiological changes in the different hippocampal circuits.

The known increased excitability of principal excitatory neurons, which is one of the hallmarks of aging in the hippocampus, might also result from the different intrinsic efficiency of presynaptic modulation systems. We now confirmed that there was an age-related reduction in the density of inhibitory $A_{1}$ receptors (Fig. 2A), in agreement 
$(A)$
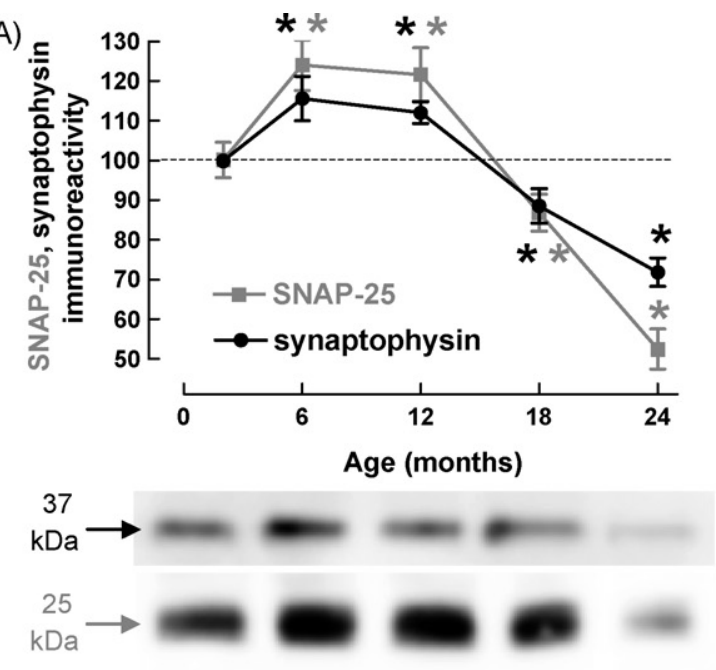

(C)
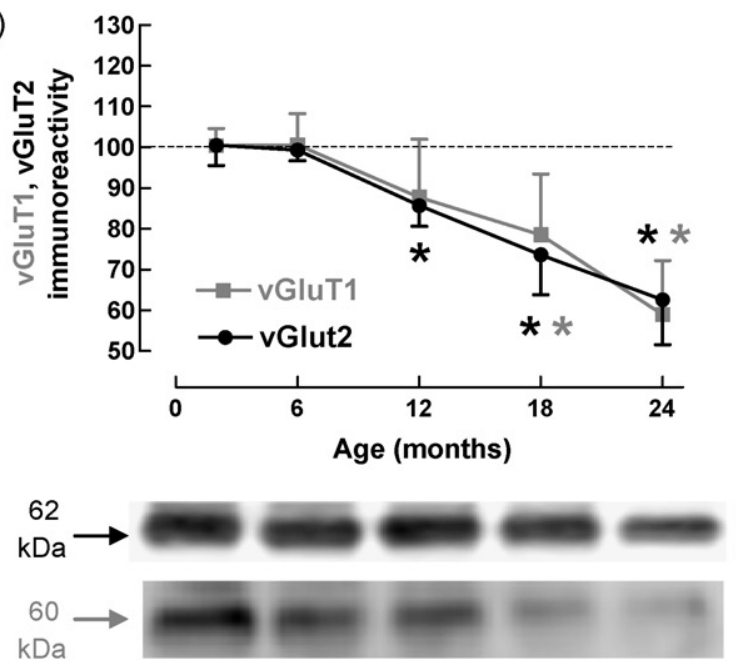

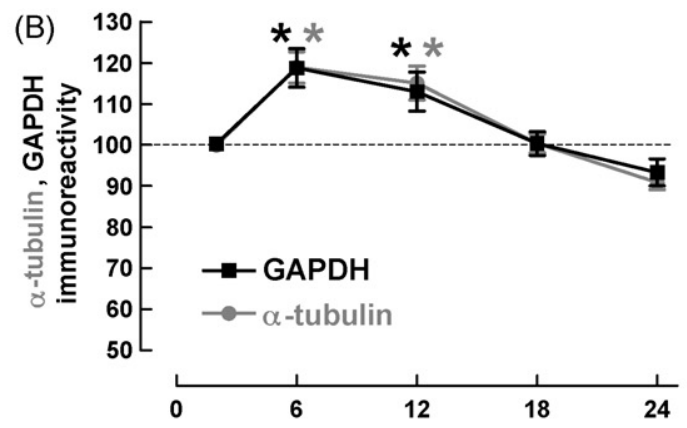

Age (months)
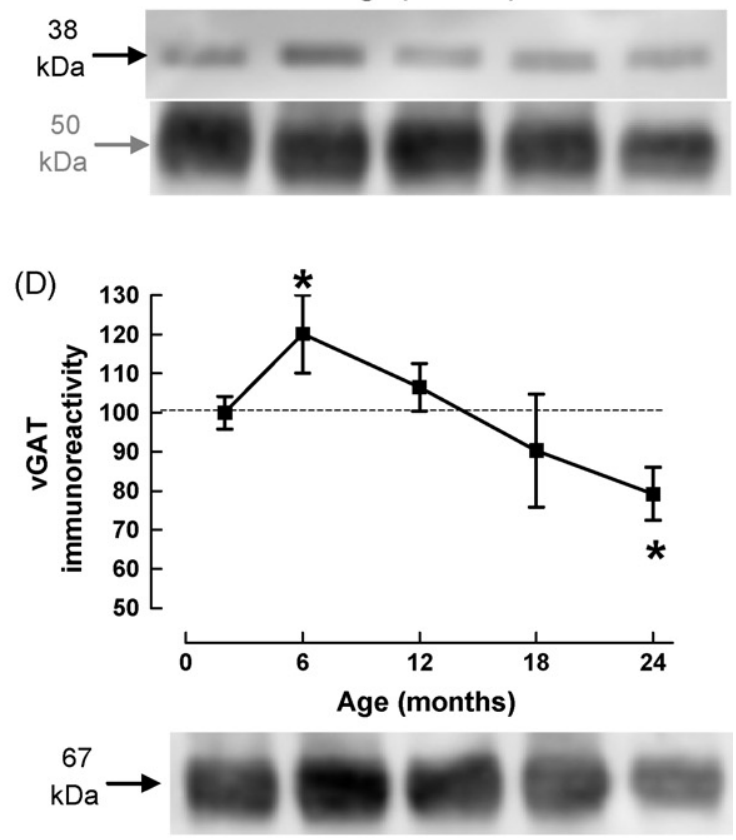
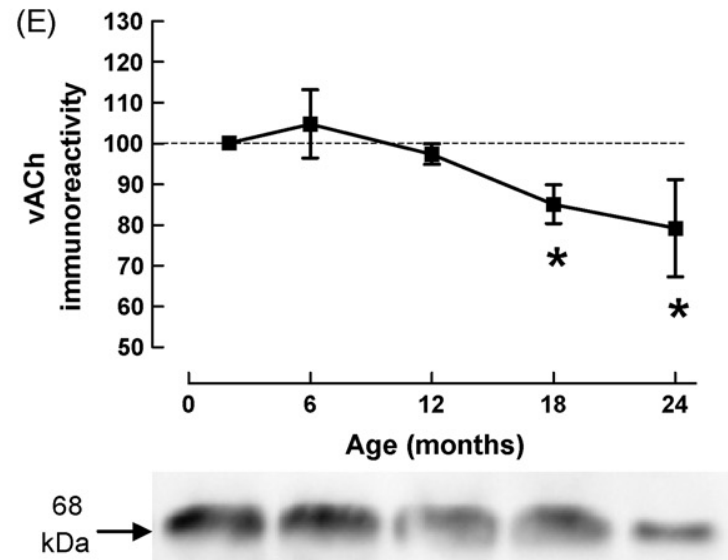

Fig. 1. Age-related changes in the density of presynaptic markers (synaptophysin and SNAP-25 (A)), general cytoplasmatic markers ( $\alpha$-tubulin and glyceraldeheyde-3-phosphate dehydrogenase, GAPDH (B)), markers of glutamatergic terminals (vesicular glutamate transporters types 1 and 2, vGluT1 and 2 (C)), markers of GABAergic terminals (vesicular GABA transporter, vGAT (D)) and markers of cholinergic terminals (vesicular acetylcholine transporter, vAChT (E)) in nerve terminals purified from the hippocampus of rats with different ages (2, 6, 12, 18 and 24 months). Each panel displays the percentage density of each protein compared to its density at 2 months and the data was derived from Western blot analysis similar to that indicated below each graph where all age groups were simultaneously evaluated. The results are mean \pm S.E.M. of $4-8$ animals in each age group. $* P<0.05$ compared to 2 months. 
(A)
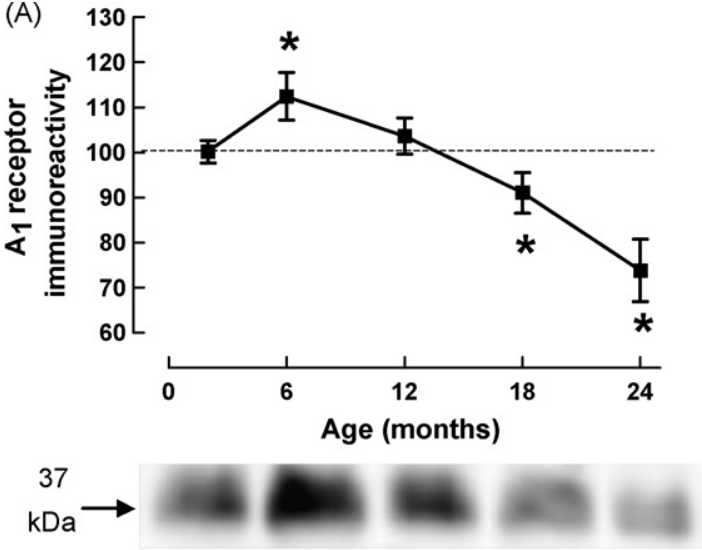

(C)
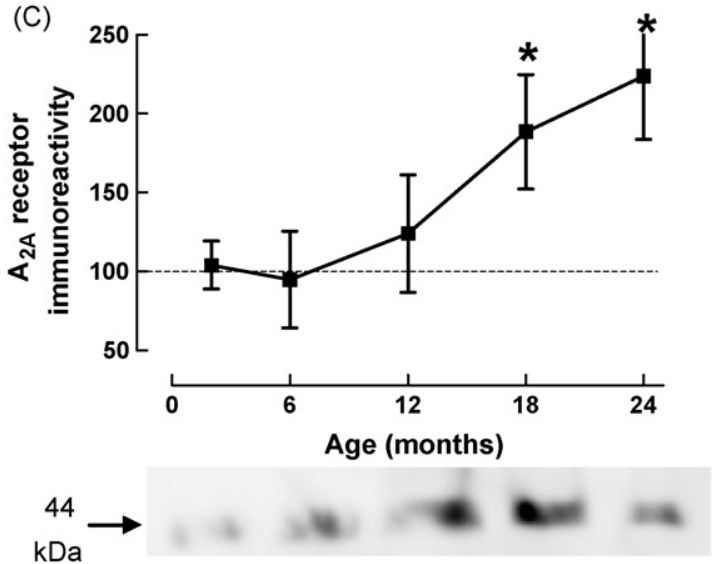
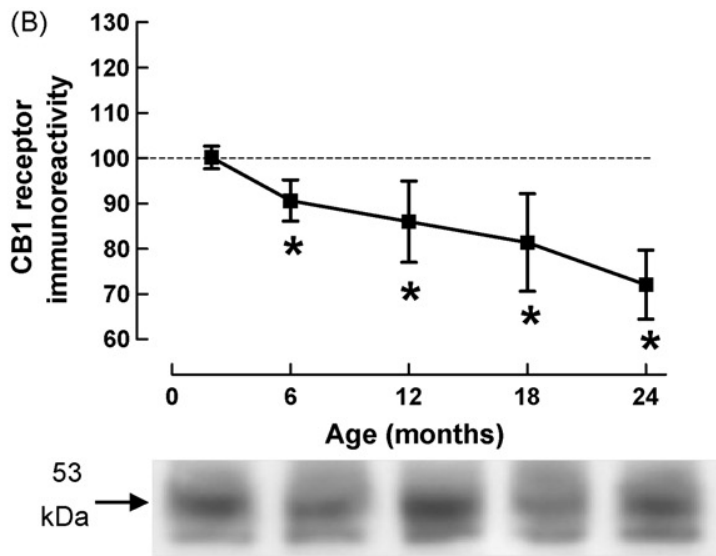

(D)
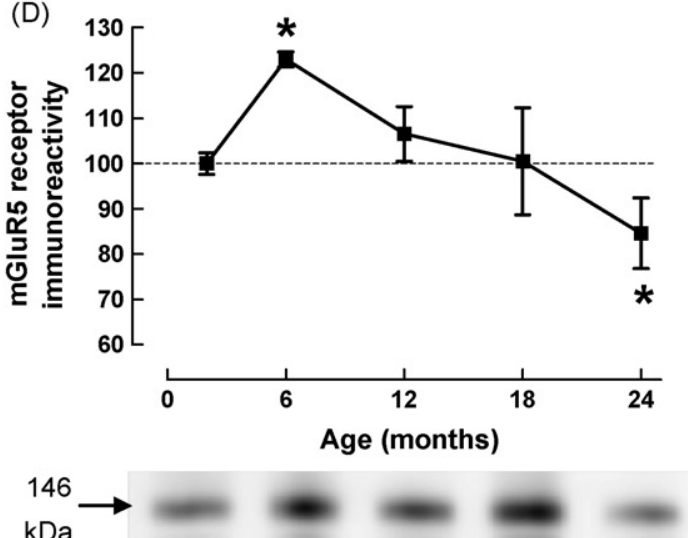

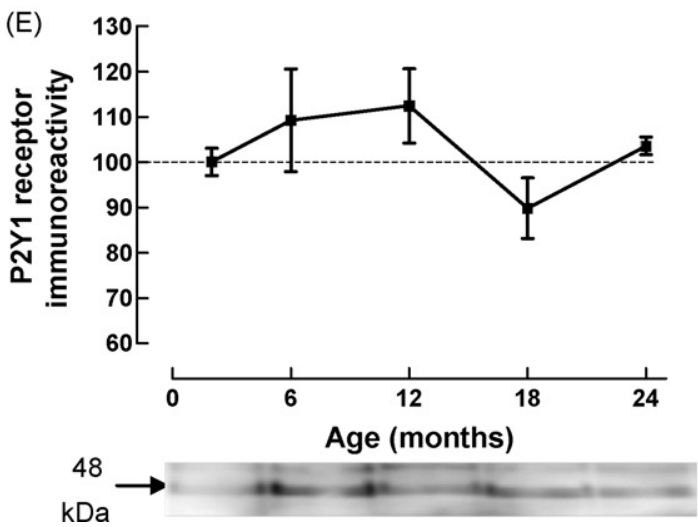

Fig. 2. Age-related changes in the density of receptors operating presynaptic modulation systems that have been targeted as neuroprotective strategies, namely adenosine $A_{1}$ receptors $(A)$, cannabinoid $C_{1}$ receptors $(B)$, adenosine $A_{2 A}$ receptors $(C)$, glutamate metabotropic group 5 receptors (mGluR5 (D)) and purinergic P2Y1 receptors (E) in nerve terminals purified from the hippocampus of rats with different ages (2, 6, 12, 18 and 24 months). Each panel displays the percentage density of each receptor compared to its density at 2 months and the data was derived from Western blot analysis similar to that indicated below each graph where all age groups were simultaneously evaluated. The results are mean \pm S.E.M. of $4-8$ animals in each age group. $* P<0.05$ compared to 2 months.

with previous observations (Cheng et al., 2000; Cunha et al., 1995; Pagonopoulou and Angelatou, 1992). This powerful $A_{1}$ receptor-mediated presynaptic inhibitory system mostly affects excitatory rather than inhibitory transmission in cortical circuits (reviewed in Fredholm et al., 2005) and we have previously shown that the $A_{1}$ receptor-mediated inhibition of excitatory transmission in the hippocampus is decreased in aged rats (Sebastião et al., 2000). Thus, the reduced density of $A_{1}$ receptors in aged rats may contribute for the increased excitability of principal neurons upon aging (Barnes, 1994). On the hand, it also suggests that strategies targeting $\mathrm{A}_{1}$ receptors to manage neurodegenerative diseases (reviewed in Fredholm et al., 2005) may be less efficient in aged animals. 
The density of cannabinoid $\mathrm{CB}_{1}$ receptors, which operates another presynaptic inhibitory modulation system (van der Stelt and Di Marzo, 2005) was also found to be decreased with aging (Fig. 2B). This is in agreement with the age-related decreased expression of $\mathrm{CB}_{1}$ receptors in the hippocampus (Berrendero et al., 1998), although different age-related changes in $\mathrm{CB}_{1}$ protein density were reported in different cortical regions (Berrendero et al., 1998; Liu et al., 2003; Mato and Pazos, 2004). In contrast to $A_{1}$ receptors, $C_{1}$ receptors inhibit both excitatory and inhibitory transmission in the hippocampus (van der Stelt and Di Marzo, 2005), although the neuroprotective effects associated with $\mathrm{CB}_{1}$ receptors were ascribed to glutamatergic rather than GABAergic effects (Monory et al., 2006). However, this decrease in the density of $\mathrm{CB}_{1}$ receptors with aging suggests that the efficacy of targeting $\mathrm{CB}_{1}$ receptors to manage neuronal dysfunction in the elderly might be lower than that anticipated based on the studies carried out in young adults.

In contrast to the age-related change in the density of the receptors operating these two main presynaptic inhibitory systems, we found a significant increase in the density of the adenosine $\mathrm{A}_{2 \mathrm{~A}}$ receptors (Fig. 1C). $\mathrm{A}_{2 \mathrm{~A}}$ receptors trigger a presynaptic facilitation system which increases glutamatergic transmission and plasticity (reviewed in Fredholm et al., 2005 ) and the present results confirm previous observations that the increased density of hippocampal $\mathrm{A}_{2 \mathrm{~A}}$ receptors mainly occurs from middle-aged to aged animals (Rebola et al., 2003a). This age-related increase of the density of $\mathrm{A}_{2 \mathrm{~A}}$ receptors is particularly interesting in view of the ability of $\mathrm{A}_{2 \mathrm{~A}}$ receptor antagonists to restore memory dysfunction associated with aging (Prediger et al., 2005) and neurodegenerative diseases (Dall'Igna et al., 2007).

Another facilitation system which antagonism affords neuroprotection is operated by metabotropic group 5 receptors (mGluR5), although their mechanism of action is still unclear due to their pre-, post- and non-neuronal localization (reviewed in Flor et al., 2002). It has previously been reported that the global ability of mGluR5 to recruit phosphoinositide turnover is blunted (Nicolle et al., 1999b), whereas their post-synaptic effects on membrane properties are largely preserved in aged rats (Jouvenceau et al., 1997) in agreement with the preservation of mGluR5 density in the aged hippocampus (Jouvenceau et al., 1997; Nicolle et al., 1999b; Simonyi et al., 2005). We now observed that the density of mGluR5 increased at 6 months and was maintained throughout aging, with only a marginal reduction observed at 24 months (Fig. 2D). In fact, the normalization of mGluR5 density using cytoplasmatic markers ( $\alpha$-tubulin and GAPDH) offsets any significant modifications of the density of mGluR5 $(P>0.05)$. This suggests that the synaptoprotective effects associated with the control of mGluR5 action might essentially be preserved with aging.

Finally, the last presynaptic modulation system investigated in this study was the P2Y1 receptor. We have recently found that the blockade of this receptor affords a robust neuroprotection against damage of hippocampal neurons in different models of excitotoxicity (unpublished results) in agreement with the neuroprotection afforded by P2Y receptor antagonists in in vivo models of ischemia (Franke et al., 2006). We now found that the density of presynaptic hippocampal $\mathrm{P} 2 \mathrm{Y} 1$ receptors is similar $(P>0.05)$ in all age groups tested (Fig. 2E). This indicates that this presynaptic modulation is preserved upon aging, suggesting that it may be an interesting target to control age-related neurodegenerative processes.

When evaluated globally, the results obtained prompt a trend in terms of age-related changes in the density of presynaptic modulation systems. In fact, there seems to be a clear reduction in the density of receptors operating inhibitory systems ( $\mathrm{A}_{1}$ and $\mathrm{CB}_{1}$ receptors) paralleled by a trend towards the preservation (mgluR5) or clear increase $\left(\mathrm{A}_{2 \mathrm{~A}}\right.$ receptors) of presynaptic facilitation systems. This is a remarkable agreement with the hallmark of increased excitability that characterizes principal neurons in hippocampal circuits of aged rats. However, the age-related changes described in this study are total changes in the density of receptors and transporters, which do not discriminate between intracellular and membrane bound proteins. Hence, the present findings do not provide information about eventual changes in receptor reserve. Therefore, this tentative relation based on the agerelated changes in the density of protein receptors still needs to be explored at the functional level. Another interesting inference derived from the data presented is that the neuroprotective strategies targeting presynaptic modulation system that seem best fitted to be transposed to the management of neurodegenerative diseases in the elderly are these based on the use of antagonists. In fact, antagonists of mGluR5, $\mathrm{A}_{2 \mathrm{~A}}$ and $\mathrm{P} 2 \mathrm{Y} 1$ receptors are proposed as candidate neuroprotective strategies and the density of these presynaptic receptors is either preserved or increased on aging. In contrast, agonists of $A_{1}$ and $C_{1}$ receptors are proposed as candidate neuroprotective strategies and the density of these presynaptic receptors is decreased. This prompts the question of whether the age-related decrease of these inhibitory receptor systems is due to their intense recruitment to counteract age-related deleterious changes in hippocampal circuits. Conversely, the participation of each of the facilitation receptors in the age-related changes of neuronal circuits is still an open question.

\section{Conflicts of interest}

None.

\section{Acknowledgments}

We thank Nelson Rebola for his continuous help in this project and John Jones for kindly reviewing the manuscript. The work was supported by Fundação para a Ciência e Tecnologia (POCI/SAU-FCF/59601/2004) and by a Pfizer Award from the Portuguese Society of Neuroscience. 


\section{References}

Barnes, C.A., 1994. Normal aging: regionally specific changes in hippocampal synaptic transmission. Trends Neurosci. 17, 13-18.

Benice, T.S., Rizk, A., Kohama, S., Pfankuch, T., Raber, J., 2006. Sexdifferences in age-related cognitive decline in C57BL/6J mice associated with increased brain microtubule-associated protein 2 and synaptophysin immunoreactivity. Neuroscience 137, 413-423.

Berrendero, F., Romero, J., García-Gil, L., Suarez, I., De la Cruz, P., Ramos, J.A., Fernández-Ruiz, J.J., 1998. Changes in cannabinoid receptor binding and mRNA levels in several brain regions of aged rats. Biochim. Biophys. Acta 1407, 205-214.

Bézard, E., Gross, C.E., Brotchie, J.M., 2003. Presymptomatic compensation in Parkinson's disease is not dopamine-mediated. Trends Neurosci. 26, 215-221.

Calhoun, M.E., Kurth, D., Phinney, A.L., Long, J.M., Hengemihle, J., Mouton, P.R., Ingram, D.K., Jucker, M., 1998. Hippocampal neuron and synaptophysin-positive bouton number in aging C57BL/6 mice. Neurobiol. Aging 19, 599-606.

Chen, K.S., Masliah, E., Mallory, M., Gage, F.H., 1995. Synaptic loss in cognitively impaired aged rats is ameliorated by chronic human nerve growth factor infusion. Neuroscience 68, 19-27.

Cheng, J.T., Liu, I.M., Juang, S.W., Jou, S.B., 2000. Decrease of adenosine $\mathrm{A}_{1}$ receptor gene expression in cerebral cortex of aged rats. Neurosci. Lett. 283, 227-229.

Cunha, R.A., Constantino, M.C., Sebastião, A.M., Ribeiro, J.A., 1995. Modification of $A_{1}$ and $A_{2 A}$ adenosine receptor binding in aged striatum, hippocampus and cortex of the rat. Neuroreport 6, 1583-1588.

Cunha, R.A., Almeida, T., Ribeiro, J.A., 2001. Parallel modification of adenosine extracellular metabolism and modulatory action in the hippocampus of aged rats. J. Neurochem. 76, 372-382.

Dall'Igna, O.P., Fett, P., Gomes, M.W., Souza, D.O., Cunha, R.A., Lara, D.R., 2007. Caffeine and adenosine $A_{2 A}$ receptor antagonists prevent $\beta$-amyloid (25-35)-induced cognitive deficits in mice. Exp. Neurol. 203, 241-245.

Eastwood, S.L., Burnet, P.W.J., McDonald, B., Clinton, J., Harrison, P.J., 1994. Synaptophysin gene expression in human brain: a quantitative in situ hybridization and immunocytochemical study. Neuroscience 59, 881-892.

Eastwood, S.L., Weickert, C.S., Webster, M.J., Herman, M.M., Kleinman, J.E., Harrison, P.J., 2006. Synaptophysin protein and mRNA expression in the human hippocampal formation from birth to old age. Hippocampus $16,645-654$.

Ferrer, I., 2002. Synaptic pathology and cell death in the cerebellum in Creutzfeldt-Jakob disease. Cerebellum 1, 213-222.

Flor, P.J., Battaglia, G., Nicoletti, F., Gasparini, F., Bruno, V., 2002. Neuroprotective activity of metabotropic glutamate receptor ligands. Adv. Exp. Med. Biol. 513, 197-223.

Franke, H., Krügel, U., Illes, P., 2006. P2 receptors and neuronal injury. Pflüg. Arch. 452, 622-644.

Fredholm, B.B., Chen, J.F., Cunha, R.A., Svenningsson, P., Vaugeois, J.M., 2005. Adenosine and brain function. Int. Rev. Neurobiol. 63, 191-270.

Frick, K.M., Fernandez, S.M., 2003. Enrichment enhances spatial memory and increases synaptophysin levels in aged female mice. Neurobiol. Aging 24, 615-626.

Garden, G.A., Budd, S.L., Tsai, E., Hanson, L., Kaul, M., D'Emilia, D.M., Friedlander, R.M., Yuan, J., Masliah, E., Lipton, S.A., 2002. Caspase cascades in human immunodeficiency virus-associated neurodegeneration. J. Neurosci. 22, 4015-4024.

Glantz, L.A., Gilmore, J.H., Lieberman, J.A., Jarskog, L.F., 2006. Apoptotic mechanisms and the synaptic pathology of schizophrenia. Schizophr. Res. 81, 47-63.

Herkenham, M., Little, M.D., Bankiewicz, K., Yang, S.C., Markey, S.P., Johannessen, J.N., 1991. Selective retention of MPP+ within the monoaminergic systems of the primate brain following MPTP administration: an in vivo autoradiographic study. Neuroscience 40, 133-158.
Himeda, T., Mizuno, K., Kato, H., Araki, T., 2005. Effects of age on immunohistochemical changes in the mouse hippocampus. Mech. Ageing Dev. 126, 673-677.

Jouvenceau, A., Dutar, P., Billard, J.M., 1997. Is activation of the metabotropic glutamate receptors impaired in the hippocampal CA1 area of the aged rat? Hippocampus 7, 455-459.

King, D.L., Arendash, G.W., 2002. Maintained synaptophysin immunoreactivity in $\mathrm{Tg} 2576$ transgenic mice during aging: correlations with cognitive impairment. Brain Res. 926, 58-68.

Köfalvi, A., Rodrigues, R.J., Ledent, C., Mackie, K., Vizi, E.S., Cunha, R.A., Sperlágh, B., 2005. Involvement of cannabinoid receptors in the regulation of neurotransmitter release in the rodent striatum: a combined immunochemical and pharmacological analysis. J. Neurosci. 25, 2874-2884.

Li, H., Li, S.H., Yu, Z.X., Shelbourne, P., Li, X.J., 2001. Huntingtin aggregate-associated axonal degeneration is an early pathological event in Huntington's disease mice. J. Neurosci. 21, 8473-8481.

Liu, P., Bilkey, D.K., Darlington, C.L., Smith, P.F., 2003. Cannabinoid CB1 receptor protein expression in the rat hippocampus and entorhinal, perirhinal, postrhinal and temporal cortices: regional variations and age-related changes. Brain Res. 979, 235-239.

Lopes, L.V., Cunha, R.A., Ribeiro, J.A., 1999. Increase in the number, G protein coupling, and efficiency of facilitatory adenosine $\mathrm{A}_{2 \mathrm{~A}}$ receptors in the limbic cortex, but not striatum, of aged rats. J. Neurochem. 73, 1733-1738.

Masliah, E., Mallory, M., Hansen, L., DeTeresa, R., Terry, R.D., 1993. Quantitative synaptic alterations in the human neocortex during normal aging. Neurology 43, 192-197.

Mato, S., Pazos, A., 2004. Influence of age, postmortem delay and freezing storage period on cannabinoid receptor density and functionality in human brain. Neuropharmacology 46, 716-726.

Monory, K., Massa, F., Egertová, M., Eder, M., Blaudzun, H., Westenbroek, R., Kelsch, W., Jacob, W., Marsch, R., Ekker, M., Long, J., Rubenstein, J.L., Goebbels, S., Nave, K.A., During, M., Klugmann, M., Wölfel, B., Dodt, H.U., Zieglgänsberger, W., Wotjak, C.T., Mackie, K., Elphick, M.R., Marsicano, G., Lutz, B., 2006. The endocannabinoid system controls key epileptogenic circuits in the hippocampus. Neuron 51, 455-466.

Nicolle, M.M., Gallagher, M., McKinney, M., 1999a. No loss of synaptic proteins in the hippocampus of aged, behaviorally impaired rats. Neurobiol. Aging 20, 343-348.

Nicolle, M.M., Colombo, P.J., Gallagher, M., McKinney, M., 1999b. Metabotropic glutamate receptor-mediated hippocampal phosphoinositide turnover is blunted in spatial learning-impaired aged rats. J. Neurosci. 19, 9604-9610.

Pagonopoulou, O., Angelatou, F., 1992. Reduction of $A_{1}$ adenosine receptors in cortex, hippocampus and cerebellum in ageing mouse brain. Neuroreport 3, 735-737.

Pinheiro, P.C., Rodrigues, R.J., Silva, A.P., Cunha, R.A., Oliveira, C.R., Malva, J.O., 2003. Solubilization and immunological identification of presynaptic $\alpha$-amino-3-hydroxy-5-methyl-4-isoxazolepropionic acid receptors in the rat hippocampus. Neurosci. Lett. 336, 97-100.

Prediger, R.D., Batista, L.C., Takahashi, R.N., 2005. Caffeine reverses age-related deficits in olfactory discrimination and social recognition memory in rats Involvement of adenosine $\mathrm{A}_{1}$ and $\mathrm{A}_{2 \mathrm{~A}}$ receptors. Neurobiol. Aging 26, 957-964.

Raff, M.C., Whitmore, A.V., Finn, J.T., 2002. Axonal self-destruction and neurodegeneration. Science 296, 868-871.

Ratté, S., Lacaille, J.C., 2006. Selective degeneration and synaptic reorganization of hippocampal interneurons in a chronic model of temporal lobe epilepsy. Adv. Neurol. 97, 69-76.

Rebola, N., Sebastião, A.M., de Mendonça, A., Oliveira, C.R., Ribeiro, J.A., Cunha, R.A., 2003a. Enhanced adenosine $\mathrm{A}_{2 \mathrm{~A}}$ receptor facilitation of synaptic transmission in the hippocampus of aged rats. J. Neurophysiol. 90, 1295-1303.

Rebola, N., Pinheiro, P.C., Oliveira, C.R., Malva, J.O., Cunha, R.A., 2003b. Subcellular localization of adenosine $A_{1}$ receptors in nerve terminals and synapses of the rat hippocampus. Brain Res. 987, 49-58. 
Rebola, N., Canas, P.M., Oliveira, C.R., Cunha, R.A., 2005. Different synaptic and subsynaptic localization of adenosine $A_{2 A}$ receptors in the hippocampus and striatum of the rat. Neuroscience 132, 893-903.

Rodrigues, R.J., Almeida, T., Richardson, P.J., Oliveira, C.R., Cunha, R.A., 2005a. Dual presynaptic control by ATP of glutamate release via facilitatory P2X1, P2X2/3 and P2X3, and inhibitory P2Y1 P2Y2 and/or P2Y4 receptors in the rat hippocampus. J. Neurosci. 27, 6286-6295.

Rodrigues, R.J., Alfaro, T.M., Rebola, N., Oliveira, C.R., Cunha, R.A., 2005b. Co-localization and functional interaction between adenosine $\mathrm{A}_{2 \mathrm{~A}}$ and metabotropic group 5 receptors in glutamatergic nerve terminals of the rat striatum. J. Neurochem. 92, 433-441.

Rodrigues, R.J., Canas, P.M., Lopes, L.V., Oliveira, C.R., Cunha, R.A., in press. Modification of adenosine receptor modulation of acetylcholine release in the hippocampus of aged rats. Neurobiol. Aging, doi:10.1016/j.neurobiolaging.2007.03.025.

Rutten, B.P., Van der Kolk, N.M., Schafer, S., van Zandvoort, M.A., Bayer, T.A., Steinbusch, H.W., Schmitz, C., 2005. Age-related loss of synaptophysin immunoreactive presynaptic boutons within the hippocampus of APP751SL, PS1M146L, and APP751SL/PS1M146L transgenic mice. Am. J. Pathol. 167, 161-173.

Saito, S., Kobayashi, S., Ohashi, Y., Igarashi, M., Komiya, Y., Ando, S., 1994. Decreased synaptic density in aged brains and its prevention by rearing under enriched environment as revealed by synaptophysin contents. J. Neurosci. Res. 39, 57-62.

Sarter, M., Bruno, J.P., 2004. Developmental origins of the age-related decline in cortical cholinergic function and associated cognitive abilities. Neurobiol. Aging 25, 1127-1139.
Sebastião, A.M., Cunha, R.A., de Mendonça, A., Ribeiro, J.A., 2000. Modification of adenosine modulation of synaptic transmission in the hippocampus of aged rats. Br. J. Pharmacol. 131, 1629-1634.

Selkoe, D.J., 2002. Alzheimer's disease is a synaptic failure. Science 298 , 789-791.

Shi, L., Argenta, A.E., Winseck, A.K., Brunso-Bechtold, J.K., 2004. Stereological quantification of GAD-67-immunoreactive neurons and boutons in the hippocampus of middle-aged and old Fischer 344x Brown Norway rats. J. Comp. Neurol. 478, 282-291.

Simonyi, A., Ngomba, R.T., Storto, M., Catania, M.V., Miller, L.A., Youngs, B., DiGiorgi-Gerevini, V., Nicoletti, F., Sun, G.Y., 2005. Expression of groups I and II metabotropic glutamate receptors in the rat brain during aging. Brain Res. 1043, 95-106.

van der Stelt, M., Di Marzo, V., 2005. Cannabinoid receptors and their role in neuroprotection. Neuromol. Med. 7, 37-50.

Wishart, T.M., Parson, S.H., Gillingwater, T.H., 2006. Synaptic vulnerability in neurodegenerative disease. J. Neuropathol. Exp. Neurol. 65, 733739.

Wong, T.P., Marchese, G., Casu, M.A., Ribeiro-da-Silva, A., Cuello, A.C., De Koninck, Y., 2000. Loss of presynaptic and postsynaptic structures is accompanied by compensatory increase in action potential-dependent synaptic input to layer $\mathrm{V}$ neocortical pyramidal neurons in aged rats. J. Neurosci. 20, 8596-8606.

Wong, T.P., Marchese, G., Casu, M.A., Ribeiro-da-Silva, A., Cuello, A.C., De Koninck, Y., 2006. Imbalance towards inhibition as a substrate of aging-associated cognitive impairment. Neurosci. Lett. 397, 64 68 . 